\title{
9th World Congress for Disaster and Emergency Medicine
}

\section{Oral Presentations}

\author{
29 MAY 1995
}

132.

Medical Response and Preparedness for

Maritime Transportation Disasters in

Singapore

Dr. V. Anantharaman

Accident and Emergency Department,

Singapore General Hospital, Singapore

Singapore owed much of its economic development to its strategic location in Southeast Asia. Singapore lies along the major air and sea lanes linking the east with the west. Therefore, it is not surprising that it is amongst the busiest ports in the world. The local authority has developed a contingency plan, the Ferry Mishap Plan, to provide an integrated response to a potential disaster which involves a domestic passenger ferry that services the southern islands of Singapore and the nearby islands of Riau, Indonesia. This was considered most likely scenario at that time. This plan was exercised annually.

On 23 August 1992, the M.V. Royal Pacific, a cruise ship with more than 500 persons on board, collided with a fishing vessel in the Straits of Malacca about 150 nautical miles from Singapore. The Ferry Mishap Plan, which was scheduled to be exercised a week later, was activated. Many adjustments had to be made to the plan to adapt to a disaster of this magnitude.

Lessons learned from this disaster were compared against those lessons and issues compiled from a retrospective analysis of postmortem transcripts of previous exercises. It was found that reality and exercises often do present the same problems. However, it was concluded that all plans must be flexible and easily adaptable to varying conditions. An example is that medical elements must have the capability to be mobile and be able to be inserted as close to the disaster site as early as possible.

036.

Workshop: Airway Management under Adverse Conditions

Dr. G. Petroianu, ${ }^{1}$ Dr. J. Fisher, ${ }^{2}$ Dr. E. Frimberger, ${ }^{3}$ Dr. W. Maleck, ${ }^{4}$ Dr. W. Bergler, ${ }^{4}$ Dr. E. Dykstra ${ }^{5}$

${ }^{1}$ Heidelberg/Mannheim, Germany; ${ }^{2}$ Toronto, Canada;

${ }^{3}$ Munich, Germany; ${ }^{4}$ Mannheim, Germany ; and ${ }^{5}$ Wiesbaden, Germany

\section{PROGRAM}

1. Introduction

E. Dykstra, G. Petroianu
Importance of ventilation vs. intubation, failure to intubate; failure to recognize esophageal tube position.

2. How to decide when to intubate?

J. Fisher

Easy-to-use algorithm in- or out-of-hospital.

3. Detection of incorrect ET-tube placement in the "out-ofhospital" setting

G. Petroianu

ODD, EasyCap, StatCap, PediCap, MiniCap, Colibri, and Light-Wand are introduced; advantages and limitations are discussed.

4. Predicting the difficult intubation: Science or crystal-ball gazing?

W. Maleck

Predicting "trouble," intubation despite anatomical difficulties: special blades and tubes.

5. The BSR technique: A new method for easy-to-learn manual ventilation

\section{E. Frimberger}

The serious problem of ineffective manual ventilation;

Resuscitation with the CardioVent: A new solution to the same old problems?

6. Establishing a surgical airway in the "out-of-hospital" setting W. Bergler

A surgeon's perspective.

\section{5.}

\section{Doorstep Physio-Therapy/Rehabilitation Services to Earthquake Victims}

Dr. V.S. Chauhan

Project Director, AMDA-India

The devastating earthquake in Maharashtra State of India on 30 September 1993 rendered hundreds of thousands of people homeless and severely injured several thousand more. Our headquarters in Okayama, Japan, immediately arranged to send its disaster evaluation team to the affected villages.

Considering the great number of orthopaedically injured cares, AMDA-India decided to provide door-to-door, long-term physiotherapy services in at least $50 \%$ of the affected areas. To achieve this goal, a special, made-to-order vehicle was pressed into service. This vehicle is equipped with all of the sophisti- 
cated physiotherapy instruments that could operate on a battery, so they could be used in smaller villages. It also contained a mobile X-ray machine. Allied services offered included supplies of prosthetics, wheelchairs, etc., and the free hospitalization and surgeons services through honorary consultants.

This project completed one year of operation on $31 \mathrm{March}$ 1995. So far, it has served around 400,000 of the population; and with the help of one full-time doctor and physiotherapist, has served around 1,528 patients in 42 villages. This is a pioneering effort for the restoration of the physical health of disaster victims.

087.

\section{Emergency Medical Care for Victims of the Great Hanshin Earthquake}

Ryo Iwai, MD, Soichiro Kasai, MD, Yasuko Kim, MD, Yoshihiro Takashima, MD, Ippei Mouri, MD, Akiko Miura

Department of Anesthesiology, University of Tsukuba, Japan

Quite a big earthquake of magnitude 7.2 (Richter scale) occurred on 17 January 1995 in Hanshin area of Japan. More than 5,000 lives were lost. We established a nongovernment organization (NGO) medical project in Nagata Ward, which is one of the most heavily damaged zones in Kobe city. We opened a 24-hour clinic in the public health center and started to provide medical care in some shelters. Given the nutritionally and environmentally bad conditions, most of the people in the shelters were suffering from a common cold. Some needed DIV and/or antibiotics. Severe dehydration due to fever and diarrhea induced pre-shock states in a few patients.

During the next stage, we managed patients with chronic diseases such as hypertension, diabetes, asthma, and mental disorders because they had left their daily drugs in their destroyed houses. The stress associated with the incident worsened their conditions. We not only waited for the patients to come to the clinic, but we went to the field and into the shelters to seek the patients. This was very important because some victims were living in places where the administration could not check, and some had no one to help take care of them. Participation of medical specialists, such as pediatricians and psychiatrists, is desirable; and logistics were also considered to be important

\section{9.}

\section{Hospital Damages at the 1995 Great Hanshin-Awaji Quake}

Tatsuro Kai, MD, Shinzo Mukainaka, MD, Muneo Ohta, MD

Osaka Prefectural Senri Critical Care Medical Center

At 05:46 hours on 17 January 1995, the worst earthquake in postwar-Japan occurred in Hanshin area (population: 2 million). The epicenter was under Awaji-shima island, $20 \mathrm{~km}$ south of the major port of Kobe city, and the intensity was magnitude 7.2 (Richter scale). This quake killed more than 5,500, injured nearly 35,700 , and left 320,000 homeless.
As we already have reported at the 8th World Congress of Disaster and Emergency Medicine, ${ }^{1}$ hospital preparedness in this area was not sufficient. After the quake, hospitals in the affected area accepted many patients, but those hospitals were confused and could not triage the victims systematically because of the lack of a hospital disaster plan. Moreover, $72 \%$ of hospitals did not have water available because of distraction of the piping system or emergency water-supply tanks; $34 \%$ did not have generator systems available because the cooling system for them required water; and $28 \%$ did not have oxygen and compressed gas supplies available because of distraction of the piping systems.

More detail will be provided concerning hospital vulnerability against earthquakes.

\section{Reference}

1. T Kai, T. Ukai, M. Ohta, E. Pretto: Hospital disaster preparedness in Osaka, Japan. Prehosprital and Disaster Medicine 1994;9:29-32.

\section{7.}

\section{Earthquake Scenarios-_A Tool for Earthquake Disaster Preparedness}

A. Shapira, L. Feldman, A. Malitzky

Seismology Division, Institute for Petroleum Research and Geophysics, Holon, Israel

One of the more difficult tasks in initiating earthquake preparedness plans is to estimate what might happen during a strong earthquake. Many of the complications relate to the fact that this is a multidisciplinary problem where different professionals speak different "languages."

We are trying to overcome this problem by preparing a detailed and practical earthquake scenarios using "Enigma," a personal computer-based Geographic Information System (GIS). Our first pilot project is the town of Eilat, located in a part of the Dead Sea rift zone, which is seismically active and potentially may produce strong earthquakes at close proximity to the town. It is the first time that actual requirements for earthquake loss assessments in Israel have been fully explored. We have undertaken to:

1) Use the Enigma GIS software (a commercial product) for database management, map zooming (from regional dimensions to neighborhood size), information overlay, and parameter computation;

2) Collect physical data such us distribution and physical dimensions of buildings, population density, building functions, critical facilities (ports, oil storage tanks, factories, etc.) and life lines;

3) Collect geological and geotechnical information such as main active faults, soil distribution, slope information, underground water levels, and geotechnical properties of the underlying soil layers;

4) Collect engineering parameters; types of structures and their associated vulnerability and expected damage matrices as a function of seismic intensities and ground-shaking parameters; and

5) Collect seismological information: distribution of seismo- 